\title{
Psychosocial and Personal Level Circumstances Associated with Antiretroviral Therapy Non-adherence among HIV Positive Antiretroviral Therapy User Clients in Debre Birhan Referral Hospital
}

\author{
Dinaol Urgessa Gita* ${ }^{1}$; Sintayehu Abebe Kebede ${ }^{2}$ \\ ${ }^{1}$ Department of Psychology, Lecturer (MA in Counseling Psychology), Jimma University, Ethiopia \\ ${ }^{2}$ Department of Psychology, Lecturer (MA in Counseling Psychology), Dilla University, Ethiopia \\ *Email: dinaolu@yahoo.com
}

http://dx.doi.org/10.18415/ijmmu.v6i5.1169

\begin{abstract}
The purpose of the study was to examine psychosocial and personal level circumstances associated with ART non-adherence among HIV positive ART user clients in Debre Birhan referral hospital. This study used cross-sectional descriptive design. A total of 122 participants were selected through simple random and purposive sampling techniques. Adherence Attitude Inventory Scale and selfreported adherence questionnaire were administered. The result of chi square analysis revealed that social support, personal self-efficacy, age, marital status, religion, educational level and occupation had significant association with non-adherence at 95\% CI, $6.371(2, \mathrm{~N}=117)=0.006, \mathrm{p}<0.05), 11.873(2, \mathrm{~N}$ $=117)=0.012, \mathrm{p}<0.05), \quad(\mathrm{x} 2) 5.630(6, \mathrm{~N}=117)=0.003, \mathrm{p}<0.05), 0.017(6, \mathrm{~N}=117)=0.014, \mathrm{p}<0.05)$ and $14.497(6,=\mathrm{N}=117)=0.025, \mathrm{p}<0.05$. No significant sex difference was observed in attitude towards ART adherence. Besides, the result of multiple regression also showed that only single, unemployment and vocational education were accounted for non- adherence to ART $(\beta=.228, \mathrm{t}(113)=2.655, \mathrm{P}<0.05)$, $(\beta=.297, \mathrm{t}(114)=3.451, \mathrm{p}<0.05)$ and $(\beta=.231, \mathrm{t}(113)=2.652, \mathrm{p}<0.05)$ respectively. Conclusively, Personal level factors; marital status (singlehood), unemployment and vocational education accounted for variance in adherence to ART. Thus, Counselors, social workers and health care providers should give adherence counseling and psycho education.
\end{abstract}

Keywords: Adherence; Antiretroviral Therapy; Clients

\section{Introduction}

Beginning from the finding of HIV/AIDS virus in1981 in USA, more than 60 million people were infected worldwide (UN/AIDS, 2009). During that time, from the total number of infected populations only half percent of them were survived. The HIV/AIDS epidemic is still continuing increasingly by affecting the lives of many populations as one of the largest public health problems in the world in the past years and years to come as well, particularly in the developing countries of which Ethiopia is a part. 
Currently, 36.7 million peoples are living with HIV/AIDS worldwide and out of this $60 \%$ are living in Sub -Saharan African countries (UN/AIDS, 2015).

Globally, in an effort to fight and treat the HIV/AIDS epidemic different intervention mechanisms have been devised through involvement of many bilateral, multilateral and nongovernmental organizations. From those innovative efforts of intervention findings, the discovery of antiretroviral therapy ( ART) to ensure the treatability of the disease by delaying the HIV virus replication and enhancing the natural immune system of individuals was the turning point (UN/AIDS, 2009).

Adherence to Antiretroviral therapy (ART) is viewed as the best weapon of fighting the viral explanation and replication as well as an indicator of life sustainability for HIV positive individuals because ART has vital role in promoting the overall health aspects of HIV positive individuals who otherwise were died before the ART discovered (WHO,2014). However, treatment efficacy depends on good adherence to ART which constitutes a serious challenge to those clients using the therapy > $95 \%$ is considered as a good adherence level. Over the past years of HIV treatment activity, worldwide access to antiretroviral therapy has greatly improved million's life of HIV infected people.

In addition to its life-prolonging effects by answering the questions of millions of people worrying about death, antiretroviral therapy can also reduce HIV transmission to uninfected people (WHO, 2010). Furthermore, antiretroviral therapy lessens morbidity, mortality, and improves quality of life (Bukenya, Mayanja, Nakamanya, Muhumuza, \& Seeley, 2019).

Following the WHO announcement to apply the antiretroviral drugs to HIV/ADIS intervention strategy, around the mid-2000's, the Ethiopian government has officially begun and ensured universal access to ART service with fee to HIV/AIDS treatment, prevention, care \& support and two years later in 2005 the Government again launched free access of ART program and the government was able to expand the treatment in different health care centers of the country (Endeshaw,2012). This has been reduced the numbers of people who have died due to HIV/AIDS related infections (MoH, 2016).

Thus, in supporting World Health Organization agenda, Ethiopia as a country and Debre Birhan town Health office planned to achieve the 90-90- 90, which means "encourage peoples for HIV testing; link those who tested positive to ART and encourage those who are liked to ART to reduce their viral load" by 2030. In this case, adherence is the most critical factor in ensuring antiretroviral therapy success and being as main input to achieve the country's plan.

\subsection{Statement of the Study Problem}

HIV infection is responsible for one of the most overwhelming human virulent disease (Iacob, Iacob, \& Jugulete, 2017).The prevalence of people living with HIV in Ethiopia was estimated at 1.1 million at the end of 2016 (FHAPCO, 2016). Subsequent to incredible turn down for decades, since 2008, $\mathrm{HIV}$ incidence rate began to rise by $10 \%$ and number of new infection diagnosed each year increased by $36 \%$ among all ages and doubled among adults in Ethiopia (Tadele, Abebaw \& Abdulsemed, 2018). In line with HIV infection, even though the annual number of deaths from AIDS-related illness among people living with HIV (all ages) has declined, current achievement is far below the General Assembly's 2020 milestone that requires stalwart actions (Sidibé, 2018). Thus, to handle AIDS related death, even though ART adherence counseling has been initiated in various health settings, a substantial number of patients fail to adhere due to a variety of reasons (Ethiopia Country/Regional Operational Plan 2017). Many do not follow prescribed regimen (Li, Lee, Wen, Lin, Wan \& Jiraphongsa, 2010). 
According to study conducted by, Bukenya and others (2019) environmental, social, economic and behavioral experiences of people living with HIV with poor viral suppression explain their nonadherence to long term ART. Liranso and his colleagues (2017) study also revealed psychosocial circumstances which is self-efficacy to compliance; social support, subjective norms, belief system and perceived behavioral control, and various cultural factors may uniquely contribute to deeper and potential barriers to ART adherence ( Liranso, Singhe \& Eyerus 2017).

Ethiopia has nine regions and two city councils and the Amhara region of Ethiopia is one of the hardest hit with the HIV epidemic. The Amhara region of Ethiopia also has the highest number of people living with HIV/AIDS at 379,096 in 2011 (ARHPC, 2014). Debre Birhan town, had an estimated population of about 140,000 and 1.5\% of prevalence (Debre Birhan town Health office, 2016). This suggests that Debre Birhan town is one of the urban cities that are seriously affected by HIV/AIDS epidemic in Ethiopia.

Even though many researchers such as Anwar (2013) had done their studies on the challenges influencing anti-retroviral therapy adherence in Ethiopia and come up with different findings, they recommended the need of further studies on the issue as best solution. Only a few of them were tried to look the psychosocial variables such as attitudes towards ART, clients perceived behavioral control level and perceived social norms. There is also a little information which sex had better attitude towards ART adherence. Further, there is also a little information on socio-demographic factors as that are better predictors of adherence.

Finally, these days it is assumed that there is a gap in the service utilization of the large number of HIV positive ART user clients in this hospital and there is also lack of up to dated scientific information surrounding antiretroviral therapy adherence. Thus, the researchers had interested to research the psychosocial circumstances associated with adherence to ART among HIV positive ART user clients in Debre Birhan referral hospital to understand the challenges and barriers of the ART service usage.

\subsection{Objective of the Study}

The following research objectives were studied.

1. To scrutinize psychosocial and personal level factors associated with non-adherence to ART.

2. To examine whether there is a statistical significant sex difference in attitude towards adherence to ART.

3. To analyze the personal level factors predict good ART adherence.

\subsection{Significance of the Study}

The significance of the present study lies in its attempt to inform health professionals what psychosocial circumstances contributed to non-adherence. Furthermore, it can shed light health and humanitarian institutions, how to address non adherent patients. Besides, policy makers and Ministry of health can stretch strategies to handle noncompliance related challenges so as to achieve 90-90-90 milestone planned by General Assembly at 2020 and 2030 world health organization. 


\section{Literature Review}

\subsection{State of Antiretroviral Therapy Adherence}

The global decline in deaths from AIDS-related illness has largely been driven by progress in sub-Saharan Africa, particularly eastern and southern Africa, which is home to 53\% of the world's people living with HIV (Sidibé, 2018). With the advent of antiretroviral therapy (ART), it is now possible to control HIV (Federal HIV/AIDS Prevention and Control Office 2018). Thus, the annual number of global deaths from AIDS-related illness among people living with HIV (all ages) has declined from a peak of 1.9 million [1.4-2.7 million] in 2004 to 940000 [670 000-1 300 000] in 2017. However, it is not quick enough and attaining the General Assembly's 2020 milestone requires stalwart action to further declines of nearly 150000 deaths per year (Sidibé, 2018).

Ethiopia has observed remarkable progress over the past two decades in reducing HIV prevalence rate from 3.3 percent in 2000 to 0.9 percent in 2017, and AIDS-related deaths from 83,000 deaths in 2000 to 15,600 in 2017.Although the country has achieved significant progress records in the provision of free ART service, a little attention was given to immediate linkage to care for those who tested positive. Endeshaw (2012) stated that even if patients are linked to care, there is still need of new strategies for those who don't immediately link to ART service.

Thus, the gains made so far seem to be challenged by complacency regarding primary HIV prevention (Federal HIV/AIDS Prevention and Control Office 2018). Thus, currently the urban HIV prevalence is seven times higher than the rural HIV prevalence (Federal HIV/AIDS Prevention and Control Office, 2018).

\subsection{Psychosocial Circumstances Associated with Antiretroviral Therapy Adherence}

Various factors have been associated with poor adherence to ART. Some of them may include negative attitudes towards ART, inadequate knowledge about the therapy, interest and motivation to receive the therapy and other psychological and social factors (Harper \& Watt, 2007).

Furthermore, Lee, Milloy, Walsh, Nguyen, Wood and Kerr, (2017), suggested psychosocial circumstances which is self-efficacy; that is, one's belief in their own ability to complete a certain task play paramount role in achieving adequate levels of adherence to medication. Similarly other study revealed major psychological and social factors such as stigma and discrimination, social support, substance abuse, subjective norms, belief system and perceived behavioral control, and various cultural factors may uniquely contribute to deeper and potential barriers to ART adherence( Liranso, Singhe \& Eyerus 2017).

According to study conducted by Wadunde, Tuhebwe, Ediau, ildo Okure, Mpimbaza,Wanyenze, (2018), forgetfulness, transportation costs to the health facilities were the major reason for missing ART doses. Calvetti and his colleagues also suggested that social support together with antiretroviral treatment has an impact on physical conditions, improving immune response and quality of life of people living with HIV/AIDS (Calvetti, Giovelli. Gauer \&Moraes, 2014).

\subsection{Personal Level Circumstances Associated with Antiretroviral Therapy Adherence}

This lack of adherence to antiretroviral therapy is a multi-factorial and dynamic process which raises considerable difficulties for long-term follow-up (Iacob, Iacob,\& Jugulete, 2017). A study conducted by Kim and his collogues (2018), revealed having a history of malignancy, lower 
socioeconomic status, not visiting tertiary hospital, and being diagnosed in the earlier years were risk factors for lower adherence (Kim, Lee, Park, Bang, \& Lee, 2018). Harper and Watt, (2007) suggested socio-demographic characteristics such as age illiteracy, poverty, cultural and religious beliefs, and norms.

Bukenya, Mayanja, Nakamanya, Muhumuza, and Seeley (2019) reported environmental, social, economic and behavioral experiences of people living with HIV with poor viral suppression explain their non-adherence to long term ART. In this regard, movement from place to place for work or social activities, shame, low awareness of adherence education, drug use and use of alternative 'HIV cure' medicines some of the main factors of poor adherence. As of Wadunde, Tuhebwe, Ediau, ildo Okure, Mpimbaza and Wanyenze, (2018) study, forgetfulness, transportation costs to the health facilities were the major reason for missing ART doses. Successful clinical management of HIV-infected patients is subject to optimal adherence. Non-adherence to ART was associated with individual moderating factors and behavioral skills (Aye, Puckpinyo \& Peltzer, 2017).

\section{Methodology}

\subsection{Participants}

Cross-sectional descriptive research design was used. This design can measure the existing differences between or from among a variety of peoples service in the hospital and researchers believed that it was easy to get sample of participants required for the study. The target populations were all HIV positive clients who were receiving the ART at Debre Birhan referral hospital. The total eligible study population who met the inclusion criteria's for this study found from the ART clinic were $(\mathrm{N}=186)$ clients. As of Cohen, Mansion \& Morrison, (2011), for $\leq 200$ population sizes, at confidence level 95\% and margin of error 5\%, 132 participants is possible sample level. Accordingly, researchers adopted sample size level set by professional researchers. Thus, 122 participants were chosen using simple random sampling and purposive sampling techniques.

\section{2. $\quad$ Procedures}

The researchers dictated inclusion-exclusion criteria. Thus, ART users 18 years old and above who were receiving the therapy for at least 3 months prior to the study period and those who can give their informed consent were included. On contrary, ART users who are below 18 years old, not fully conscious and newly linked clients to ART were excluded from the study. Returned questionnaires that were collected from the 120 participants were screened, cleaned and checked for their completeness. Three responses were excluded from the final analysis since they responded carelessly and there were inconsistent answers throughout the questionnaire. Then after, the 117 completed questionnaires were analyzed through quantitative method and 5 respondents were addressed through interview method of data collection.

All the statistical analysis was conducted through Statistical Package for Social Science (SPSS version 21) software. Since the items in the scale were composed of negative and positive worded statements, reverse scoring were performed. To investigate and measure the demographic and other treatment related factors association with the ART adherence, Pearson chi-square test was used. To examine attitudinal differences between male and female towards ART adherence, independent sample t- 
test was conducted. Lastly, to identify the main predictive factors of ART adherence multiple liner regression was performed. Alpha levels were used for the creation of statistical significance.

Before the data analysis was carried out using liner regression model, researchers used chi-square analysis to check preliminary test of analysis to convert to multiple liner regression and to check confounding of variables using forward regression model. This was used to check if attitude to ART adherence have an association with the explanatory variables. Then after, a multiple linear regression analysis was conducted to select the most important covariates of attitude of adherence to ART and several predictor variables which showed significant association with the attitude of adherence to ART in the bivariate analysis using AAIS scored as a dependent variable. And, a forward entry method was used to run the analysis.

\subsection{Instruments}

The data were collected through the following instruments with the Amharic version of research participant's language. Socio-demographic characteristics such as age, sex, marital status, religion, educational level and occupation was assessed using open ended and close ended questioners. The Adherence Attitude Inventory (AAI) scale was used to test client's attitudes toward treatment adherence ART and adopted from Saal (2011) study. Besides, self-reported adherence questionnaire was used.

\section{Result and Discussion}

\subsection{Result}

\subsubsection{Psychosocial and Personal Level Circumstances of ART Adherence}

Pearson chi-square test was employed to measure the association of clients psychosocial and personal level circumstances with the categorical coded of adherence behavior (missed HIV medication and not missed the medication).

Table 1: Factors associated with non-Adherence to ART

\begin{tabular}{|c|c|c|c|}
\hline Variable & rson Chi-square value & df & Sig. \\
\hline Social support & 6.371 & 2 & $0.006^{*}$ \\
\hline Personal self-efficacy & 11.873 & 2 & $0.012 *$ \\
\hline Age & 5.630 & 8 & $0.024^{*}$ \\
\hline Marital status & 20.131 & 6 & $0.003^{*}$ \\
\hline Religion & 7.017 & 6 & $0.029 *$ \\
\hline Educational level & 12.394 & 6 & $0.014 *$ \\
\hline Occupation & 14.397 & 6 & $0.025^{*}$ \\
\hline Sex & 0.019 & 1 & 20.991 \\
\hline
\end{tabular}

Note $p^{*}$ significant at .05 level 
As can be depicted from table 1, social support, personal self-efficacy, age, marital status, religion, educational level and occupation had significant association with adherence at, 95\% CI, $\left(\mathrm{x}^{2}\right)$ $6.371(2,=\mathrm{N}=117)=0.006, p<0.05), 11.873(2,=\mathrm{N}=117)=0.012, p<0.05), 5.630(8,=\mathrm{N}=117)=0.024$, $p<0.05), 20.131(6, \mathrm{~N}=117)=0.003, p<0.05), 0.017(6,=\mathrm{N}=117)=0.029, p<0.05), 12.394(6, \mathrm{~N}=117)$ $=0.014, p<0.05)$ and $14.497(6,=\mathrm{N}=117)=0.025, p<0.05$ respectively.

Data from key informants also supported this in that:

The compatibility to ART regime among HIV positive antiretroviral therapy user clients looked promising in character that after termination of the service, when they come back with the help of other ART users, they said they are well. Thus they do not think as they are at risk. They also think that other people do not like them; so that when they come to ART service they show some characters that implies no need of coming back timely. However, some of them had strong interaction with one another and support one another both financially and ideally. Those who had good interaction with one another never miss the ART regime and they are resilient enough, have positive purpose in life and exercise health behaviors. However, this is not widely observed among large number of HIV positive antiretroviral therapy user clients. By and large, HIV positive antiretroviral therapy user clients had slow growing personal self efficacy to adherence that need more stimulation.

\subsubsection{Sex Comparisons Made on Attitude of Male and Female Respondents towards ART Adherence}

Table 2: Independent sample t-test employed to compare the attitude of respondents towards ART adherence by sex

\begin{tabular}{lllllll}
\hline & Sex of participants & $\mathrm{N}$ & $M$ & $S D$ & Df & Sig.(2-tailed) \\
\hline $\begin{array}{l}\text { Attitude } \\
\text { towards ART } \\
\text { compliance }\end{array}$ & Male & 33 & 1.69 & .465 & 115 & \\
\cline { 2 - 6 } & Female & 84 & 1.70 & .467 & .946 \\
\hline
\end{tabular}

Note $p^{*}$ significant at .05 level (2-tailed)

An independent samples t-test was performed comparing the scores of male and female respondents on adherence attitudes inventory scale to test the existence of statistically significant difference on attitude towards compliance to ART by sex. The result indicated that there is no statistical significance difference on attitude towards compliance to ART between male and female respondents with $t(115)=.946, P>.005$, two-tailed. 


\subsubsection{Identification of the Personal Level Factors Predict Adherence to ART}

Table 3: Multiple liner regression results of attitude towards adherence to ART

\begin{tabular}{llllll}
\hline & $\begin{array}{l}\text { Unstandardized } \\
\text { Coefficients }\end{array}$ & \multicolumn{2}{l}{$\begin{array}{l}\text { Standardized } \\
\text { Coefficients }\end{array}$} & $t$ & \\
& $\beta$ & $S . E$ & $\beta$ & & \\
(Constant) & 2.571 & 0.54 & & 46.537 & .000 \\
Single/never married & .214 & .081 & .228 & 2.655 & .009 \\
Unemployment & .281 & .081 & .297 & 3.451 & .001 \\
Vocational education & .242 & .091 & .231 & 2.652 & .009 \\
\hline
\end{tabular}

Note: Dependent Variable: attitude towards adherence to ART, * Significant at $P<0.05, R^{2}=0.196$, Adjusted $R^{2}=0.174$

Thus in the present study, the analysis showed that only single/never married, unemployment and vocational education was significantly predict adherence to ART $(\beta=.228, t(113)=2.655, P<0.05),(\beta$ $=.297, t(114)=3.451, p<0.05)$ and $(\beta=.231, t(113)=2.652, p<0.05)$ respectively.

As data obtained through interview also indicated:

To be adherent to ART service, various factors can encumber us. Before 3 years, various supports were given to us in order to attend ART service regularly. During then, Nongovernmental organizations and even government also support us not only by providing money and material things but by changing our wrong understanding about ourselves, how to live positive life by caring oneself and society we are dwelling. But recently, number of people becoming HIV positive is increasing and service associated with ART is lacking attention.

Another key informant also responded to the interview:

As noticed from ART report and assessments, client's life condition, educational status, their job and even their marital status made variance to adherence among HIV positive antiretroviral therapy user clients. For instance clients who were married and had family showed strong faithfulness to ART than clients who were not married and had no family. Besides, clients who had job and better education status were both compliant and adherent to ART services.

\subsection{Discussion}

The discussion is presented based on the order of research objectives and major findings of the study.

\subsubsection{Psychosocial and Personal Level Circumstances Associated with ART Adherence}

As the result section of the present study indicated, social support, personal self efficacy age, marital status, religion, educational level and occupation had significant association with adherence, (0.006, $\mathrm{P}<0.05),(0.012, \mathrm{P}<0.05),(0.024, p<0.05),(0.003, p<0.05),(0.029, p<0.05), 12.394(0.014, p<$ $0.05)$ and $(0.025, p<0.05$ respectively. 
According to Lee, Milloy, Walsh, Nguyen, Wood, and Kerr, (2017) self-efficacy which is one's belief in their own ability to complete a certain task play paramount role in achieving adequate levels of adherence to medication. Similarly, the present study revealed, participants self-efficacy had association with adherence and had bedrock in social support and other personal level factors.

Besides, the present study indicated that being single is positively related to adherence to ART. This was similar with the study by Lencha (2015) at Gobba hospital that individuals who were single were 0.223 times more likely to be adhered than married, widowed and separated individuals.

There is consistency between the present study and Akilile (2014) that occupation was an independent individual level factor for non-adherence. Study conducted by Vedhanayagam, Rajagopalan, Rajendran, and Sengodan (2016), also found that patient's lower level of monthly and annual income was contributory factor for poor adherence. It is logical that an individual who has no occupation may be nonadhered since they didn't get money for transportation costs to reach ART sites to collect their pills, attend appointment and meet their wants. Study conducted by Wadunde and his colleagues (2018), also support this. Bha et al.(2010) also found that unemployed and those who had no occupation were 2 times poorly adhered than who had an occupation.

\subsubsection{Sex Comparisons Made on Attitude towards ART Adherence}

As can be depicted in the result section, there is no sex difference observed in their level of attitude they have towards adherence to ART $(P=.946)$. This finding is consistent with different studies. For instance, a study conducted by Saal (2011) in South Africa found that there were no significant differences between male and female HIV positive ART user patients in their level of attitude. This finding also correlates with the study by Nyambura (2013) in Kenya and the Botswana study by Weiser et al. (2011) who reported similar results that indicate no gender association on attitude towards ART adherence.

In contrast to the present study, Bayew, Tefera, Fisehaye \& lemseged (2015) study result indicates that female HIV patients ART user participants had lower attitude scores compared to male participants score for male participants were psychologically well and develop positive attitude towards the importance of good adherence than female respondents. Similarly, another study done by Tsega, Srikanth \& Shewamene (2015) found that boy HIV positive male patients had good experience on receiving counseling service than female do.

\subsubsection{Identification of the Major Predictive Factors of Good Adherence}

Regarding major predictive factors of good adherence, study suggests that single/never married, unemployment and vocational education was significantly to predict adherence to ART $(P=.009),(P=$ $.001)$ and $(P=.009)$ respectively. Like the present study, a study conducted by Kayode (2012) at Nairobi Kenya found a statistical significance relationship exists between marital status and adherence to ARV medications $(p=0.043)(p<0.05)$. Respondents who were singles $(92.3 \%)$ tend to comply better to ART than other groups who were married $(87.8 \%)$ and widowed $(66.7 \%)$.

Similarly, occupation of the participants adhered to ART was the other covariate which showed significant positive impact on the ART user clients associated to ART adherence. Those who were unemployed are 0.281 times more likely to be adhered than who didn't increase ART adherence (coeff 0.281, $\mathrm{P}=0.001$ ). This finding disagrees with the study done by Yimenu (2009) that respondents who had 
occupation were 2 times to be less adhered than who do not have occupation. The possible implication for this difference may that in the present study most of the ART user clients who participated in this survey were benefited from humanitarian donors economic and nutritional support which may increase their adherence since the availability of food and finance may correlated with less personal cost.

The last factor which significantly predicts adherence to ART was vocational education. The coefficient indicates that for every one unit increase of educational level, the probability of adherence to ART increases by 0.242 times that of constant value (coeff. $0.242, P=0.009$ ). This finding was consistent with the study done by Ross et al., (2010) that with the increase of educational status the probability of being compliant to ART increases by 0.279 times.

\section{Conclusions and recommendations}

Although further work is required to gain a complete understanding of factors associated with non-adherence to ART therapy of HIV positive clients, the present study indicated social support, personal self-efficacy, participant's age, marital status, religion, educational level and occupations as personal level factors had significant association with adherence and were predictive factors also. Client's efficacy to adherence was rooted in social support and personal level factors. Furthermore, there is no significant difference in adherence to ART between male and female participants adhered to ART. Thus, the researchers stalwartly suggested that there is a need to promote and strengthen the existing qualities and keeping in mind the associated factors explored by this study so as to improve and monitor adherence through integrated intervention approaches. Moreover, different stakeholders such as psychologists, social workers and health care providers should give adherence counseling, link non adhered patients and clients who terminate compliance to health center sites, give clear instructions to patients focusing on managing the HIV medication side effects and promote social support.

\section{Author's Contribution}

Both authors conceived and designed the study. Dinaol Urgessa contributed to the interpretation of the data, editing of the manuscript, critically revised and approved the final manuscript. Sintayehu Abebe contributed to the initial data acquisition, interpretation of data, initial writing of the manuscript and approved the final manuscript.

\section{Ethics Approval and Consent to Participate}

Ethical clearance was obtained from Dilla university institution of education and behavioral sciences, department of psychology. Debre Berhan referral hospital administrations and pertinent zonal and district officials endorsed this study. Most participants had given written consent to participate in the study. Consent forms were read aloud to those who cannot read or understand it properly. All consents were translated into the local working language (Amharic) and back translated into English to ensure correct use of language. The consent content depicted the purpose of the study; procedures collect data from them, and the risks and benefits of participating in the study. The interview for HIV Positive ART user clients was conducted in private room and confidentiality of information obtained from the participants was cared for through assigning identification number rather than naming. 


\section{References}

Aklile, T. (2014). Measuring adherence level to antiretroviral treatment among adult peoples living with HIV/AIDS in Zewditu Memorial hospital. Unpublished M.A thesis, Addis Ababa University.

Amhara Region HIV/AIDS Prevention and Control Coordination Office (2014). HIV facts and figures. Retrieved from http://www.etharc.org/amhara/resohiv\%20facts\%20and\%20figures/amhara\%20HI

Anwar, S. (2013). Magnitude of antiretroviral therapy adherence and associated factors Among health centers in Akaki Kality sub city Addis Ababa. Ethiopia: Addis Ababa university.

Bayew, T.,Tefera, B., Fisehaye, A. \& lemseged, S. (2015). Predictors of adherence to antiretroviral therapy among people living with HIV/AIDS in resource-limited setting of southwest Ethiopia.AIDS Research and Therapy. Retrieved from https://www.springermedizin.de/predictors-of-adherence-to-antiretroviral.../9603968

Bha, M., Ramburth, M., Singh, O.,Titi, P., Antony, L., Chiya, E., Irusen, P.,. Mtyapi,E. and Mofoka Z.(2010). Factors associated with poor adherence to antiretroviral therapy in patients attending rural health centre in South Africa. European Journal of clinical Microbiology and Infectious Diseases. (8):947-53.

Bukenya D., Mayanja B., Nakamanya S., Muhumuza R., \& Seeley J.,(2019). What causes non-adherence among some individuals on long term antiretroviral therapy? Experiences of individuals with poor viral suppression in Uganda. Vol: 16:2 https://doi.org/10.1186/s12981-018-0214

Calvetti P., Giovelli G., Gauer G., Moraes J.,(2014). Psychosocial factors associated with adherence to treatment and quality of life in people living with HIV/AIdsin Brazi. http://dx.doi.org/10.1590/0047-2085000000002

Cohen 1., Mansion 1., and Morrison K. (2011).Research methods in education. Newyork Routledge.

Debre Birhan referral hospital. (2016).2016 annual report. Debre Birhan: Author.

Debere Birhan twon administration health office. (2016).2016 HIV/AIDS day ceremony Guideline. Debere Birhan: Author.

Endeshaw, M. (2012). Stigma: A contributing factor to depressive symptoms in people living With HIV/AIDS seeking treatment at Gondar University Hospital:University of Washington.

Ethiopia Country/Regional Operational Plan (2017). Strategic Direction Summary

Ethiopian Federal Ministry of Health. (2016). 2016 Annual report on the National effects of HIV/AID Epidemic. Addis Ababa: Ethipia.

Federal HIV/AIDS Prevention and Control Office (2018). HIV Prevention in Ethiopia National Road Map2018 - 2020

Federal Ministry of Health HIV/AIDS Prevention and Control Office (2016). HIVAIDS single Point Estimates and Projections in Ethiopia. Available from www.etharc.org/index.php//hivaidsestimates-and-projections-in-ethiopia-2011-201. 
Harper Watt, M. (2007). Understanding patients' adherence to antiretroviral therapy. Dissertation. University of North Carolinian. Tanzania.

Iacob, S., Iacob D., and Jugulete G.,(2017). Improving the Adherence to Antiretroviral Therapy, a Difficult but Essential Task for a Successful HIV Treatment - Clinical Points of View and Practical Considerations.Vol:8(831).doi: 3389/pharm.2017.00831.

Kayode A.(2012) Factors that Influence Non-Adherence to Antiretroviral Therapy Among HIV and AIDS Patients in Central Province, Kenya. p. 1-102.

Kim,J., Lee,E., Park, B., Bang,J., \& Lee J.,(2018). Adherence to antiretroviral therapy and factors affecting low medication adherence among incident HIV-infected individuals during 20092016: A nationwide study.

Lee W., Milloy M., Walsh J., Nguyen P., Wood E., Kerr T., (2017) Psychosocial factors in adherence to antiretroviral therapy among HIV-positive people who use drugs. Health Psychol. 2016 March ; 35(3): 290-297. doi:10.1037/hea0000310.

Lencha, B. (2015). Adherence to art and associated factors among people living with Hiv/aids at Gobba hospital south east Ethiopia, an institutional based study.Retrieved from www.primarycare.imedpub.com/adherence-to-anti-therapy-\&-associated-factorspdf

Liranso, G., Singhe M., Eyerus A., (2017).The Psychosocial Factors that Influencing Antiretroviral Treatment Adherence. Vol-3 Issue 1 www.openaccesspub.org DOI : 10.14302/issn.23247339.jcrhap-16-1316.

Michel Sidibé(2018). State of the epidemic: UNAIDS data.

Nyambura, A. (2013). Factors that influence adherence to ART among HIV patients in Kenya(unpublished). MA thesis. Retrieved from: www.hivaids/doc/.org.

Ross, D., Pierre, J., Fahg, Z., Hailu, T., \&Lillian, G. (2010). Measure Adherence to antiretroviral Treatment in Resource- poor Settings. The Clinical Validity of key Indicators, BMC Health Services Research10:42. Retrieved from http;//www.biomedicentral.com//1472-6963/10/42

Saal, L. (2011). The applicability of the theory of planed behavior in predicting adherence to Antiretroviral (ART) among South Africa sample: Retrieved from https://scholar.sun.ac.za/bitstream/handle/10019.1/.../saal_applicability_2011.pdf?

Tadele G., Abebaw W., Abdulsemed W.,(2018). Trend of HIV/AIDS for the last 26 years and predicting achievement of the 90-90-90 HIV prevention targets by 2020 in Ethiopia: a time series analysis https://doi.org/10.1186/s12879-018-3214-6

Tsega, B., Srikanth, B.A., \& Shewamene, Z. (2015). Determinants of non-adherence to antiretroviral therapy in adult hospitalized patients, Northwest Ethiopia. Patient Prefer Adherence, 9, 373380.

United Nation AIDS (2009). Annual report on the global AIDS epidemic .Geneva: United Nations joint program on AIDS.

United Nations AIDS. (2015). Report on the adult and children HIV estimation in the world. Geneva:United Nations. 
Vedhanayagam. M., Rajagopalan. R., Rajendran. B., and Sengodan. S. (2016). Factors associated with anti-retroviral therapy adherence among people living with HIV visiting IRT Perundurai Medical College Hospital Link ART Centre, Perundurai, Tamilnadu, India. International Journal of Advances in Medicine.3(4):982-988.

Wadunde, I., Tuhebwe D., Ediau M., ildo Okure G., Mpimbaza A.,Wanyenze R.,(2018). Factors associated with adherence to antiretroviral therapy among HIV infected children in Kabale district, Uganda: a cross sectional study. Vol: 11:466. https://doi.org/10.1186/s13104-0183575-3.

Weiser, S., Wolfe. W., Bangsberg. lemida D., and Ali. F. (2011). Barriers to antiretroviral adherence for patients living with HIV infection and AIDS in Botswana.

\section{Copyrights}

Copyright for this article is retained by the author(s), with first publication rights granted to the journal.

This is an open-access article distributed under the terms and conditions of the Creative Commons Attribution license (http://creativecommons.org/licenses/by/4.0/). 